\title{
Towards a sampling strategy for the assessment of forest condition at European level: combining country estimates
}

\author{
Davide Travaglini • Lorenzo Fattorini • \\ Anna Barbati • Francesca Bottalico • \\ Piermaria Corona - Marco Ferretti • \\ Gherardo Chirici
}

Received: 20 January 2012 / Accepted: 5 July 2012 /Published online: 3 August 2012

(C) Springer Science+Business Media B.V. 2012

\begin{abstract}
A correct characterization of the status and trend of forest condition is essential to support reporting processes at national and international level. An international forest condition monitoring has been implemented in Europe since 1987 under the auspices of the International Co-operative Programme on Assessment and Monitoring of Air Pollution Effects on Forests (ICP Forests). The monitoring is based on harmonized methodologies, with individual countries
\end{abstract}

D. Travaglini $(\bowtie) \cdot$ F. Bottalico

Dipartimento di Economia, Ingegneria, Scienze e Tecnologie Agrarie e Forestali, Università degli Studi di Firenze,

Via San Bonaventura, 13,

50145 Firenze, Italy

e-mail: davide.travaglini@unifi.it

L. Fattorini

Dipartimento di Economia Politica e Statistica, Università degli Studi di Siena,

Siena, Italy

\section{A. Barbati $\cdot$ P. Corona}

Dipartimento per l'Innovazione dei sistemi Biologici,

Agroalimentari e Forestali, Università degli Studi della Tuscia, Viterbo, Italy

\section{Ferretti}

TerraData environmetrics,

spin-off of the Università degli Studi di Siena,

Monterotondo M.mo (GR), Italy

\section{G. Chirici}

Dipartimento di Bioscienze e Territorio,

Università degli Studi del Molise,

Campobasso, Italy being responsible for its implementation. Due to inconsistencies and problems in sampling design, however, the ICP Forests network is not able to produce reliable quantitative estimates of forest condition at European and sometimes at country level. This paper proposes (1) a set of requirements for status and change assessment and (2) a harmonized sampling strategy able to provide unbiased and consistent estimators of forest condition parameters and of their changes at both country and European level. Under the assumption that a common definition of forest holds among European countries, monitoring objectives, parameters of concern and accuracy indexes are stated. On the basis of fixed-area plot sampling performed independently in each country, an unbiased and consistent estimator of forest defoliation indexes is obtained at both country and European level, together with conservative estimators of their sampling variance and power in the detection of changes. The strategy adopts a probabilistic sampling scheme based on fixed-area plots selected by means of systematic or stratified schemes. Operative guidelines for its application are provided.

Keywords Change detection - Conservative variance estimation · Design-based estimation · Fixed-area sampling $\cdot$ Forest inventory $\cdot$ Forest monitoring

\section{Introduction}

Forest resources in Europe amount to $1.02 \times 10^{9}$ ha, ca. $44.5 \%$ of land area (FOREST EUROPE et al. 2011). 